\title{
Younger supervisors, older subordinates: An organizational-level study of age differences, emotions, and performance
}

\author{
FLORIAN KUNZE ${ }^{1 *, \dagger}$ AND JOCHEN I. MENGES ${ }^{2 \dagger}$ \\ ${ }^{1}$ University of Konstanz, Chair for Organisational Studies, Konstanz, Germany \\ ${ }^{2}$ WHU - Otto Beisheim School of Management, Chair of Leadership and HRM, Düsseldorf, Germany
}

Summary

\begin{abstract}
Younger employees are often promoted into supervisory positions in which they then manage older subordinates. Do companies benefit or suffer when supervisors and subordinates have inverse age differences? In this study, we examine how average age differences between younger supervisors and older subordinates are linked to the emotions that prevail in the workforce, and to company performance. We propose that the average age differences determine how frequently older subordinates and their coworkers experience negative emotions, and that these emotion frequency levels in turn relate to company performance. The indirect relationship between age differences and performance occurs only if subordinates express their feelings toward their supervisor, but the association is neutralized if emotions are suppressed. We find consistent evidence for this theoretical model in a study of 61 companies with multiple respondents. Copyright (c) 2016 John Wiley \& Sons, Ltd.
\end{abstract}

Keywords: age norms; age diversity; relational demography; demographic change; emotions; company performance

Older employees have historically supervised younger employees (Linton 1936), but this customary pattern has changed in recent decades as a result of multiple trends (Cappeli \& Novelli 2010). To increase performance, many companies have abandoned seniority-based promotion systems and have introduced merit-based systems that encourage ambitious young employees to compete with, and overtake, their older colleagues on the corporate career ladder (Chiang \& Birtch 2007). The fast pace of technological innovation has prompted companies to appreciate the fresh and creative ideas of younger employees and consequently to promote them into supervisory positions (Posthuma \& Campion 2009). The move toward promoting younger employees into positions that require them to manage older employees is also a consequence of the demographic change (Peeters \& Groot 2012) that forces companies to retain older employees in the workplace longer than ever before, for example, through the abandoning of early retirement schemes. The ever-greater number of aging employees with flat or even downward-sloping career patterns after a certain age (e.g., 50 years) means that the likelihood of their having younger supervisors increases. Together, these trends contribute to the emergence of a "new organizational order" (Cappeli \& Novelli 2010)—one in which younger employees increasingly supervise older employees.

The neglect of age in promotion decisions has been heralded as being inherently positive-it supposedly prevents the negative feelings that age-based discrimination had created in the traditional workplace (Kunze, Boehm, \& Bruch 2011), and it motivates, through the emphasis on merit rather than seniority, high levels of company performance (Cadsby, Song, \& Tapon 2007; Dobson 1988; Lazear 2000). Most companies in industrialized countries now adhere to policies that consider age as irrelevant for promotion decisions (Castilla 2008). However, empirical evidence demonstrating the alleged benefits of these policies is mixed (Phelan \& Lin 2001). Indeed, there is a puzzle

*Correspondence to: Florian Kunze, Chair for Organisational Studies, University of Konstanz, Universitätsstr. 10, D 78457 Konstanz, Germany. E-mail: florian.kunze@uni-konstanz.de

${ }^{\dagger}$ Both authors have contributed equally to this study 
at the heart of our understanding of these developments. Theories of career time tables (Lawrence 1984, 1988) and age-related status differences (Hughes 1945; Vecchio 1993) suggest that "employees who are older than their managers will suffer negative consequences" (Shore, Cleveland, \& Goldberg 2003, p. 533). Empirical studies show that these consequences involve feeling negative emotions (Cox \& Nkomo 1992) and experiencing lower levels of performance (cf. Shore et al. 2003). These studies give reason to suspect that systematically promoting younger employees into positions requiring them to supervise older employees may diminish rather than enhance the collective feelings that prevail in a company and the company's performance.

This study addresses the question of how workers feel and collectively perform when their company features supervisory relationships pairing younger supervisors with older subordinates. We draw on extant theories about age differences in organizations (e.g., Lawrence 1984, 1988; Hughes 1945; Vecchio 1993) to develop hypotheses about age-related effects at the organizational level, and we test the hypotheses in an organizational-level survey study involving 61 companies. We propose that the average age differences between younger supervisors and their older subordinates within companies are linked to company performance. Age-inverse supervisory relationships, we suggest, carry negative emotional repercussions that, if expressed, blanket companies with negative emotions and, in turn, impair company performance.

To establish our theoretical model, we integrate relational and compositional demography theories (Tsui, Egan, \& Xin 1995), and we link those theories with emotion research at the organizational level (Menges \& Kilduff 2015). Prior research on age effects has drawn either on relational theories concerning age-different relationships as they affect employees individually (e.g., Shore et al. 2003; Tsui \& O'Reilly 1989), or on the compositional theories of age diversity as it affects the workforce collectively (e.g., Kunze, de Jong and Bruch, 2016; Van Dijk, Van Engen, \& Van Knippenberg 2012). In this research, we examine how age-different relationships within companies affect workforce emotions and performance collectively, thus bridging the two theoretical approaches. We expand our understanding of age effects at the organizational level, a level that previous research on individuals, dyads, and teams has largely neglected (Kunze et al. 2011), and we show that demographic differences link with performance through psychological mechanisms involving emotion experience and expression (Barsade \& Knight 2015; Elfenbein 2007; Menges \& Kilduff 2015). Thus, we contribute to a better understanding of how age differences in companies relate to outcomes at the organizational level.

\section{Why and when do age-inverse supervisory relationships matter?}

The organizational-level model driving our research is depicted in Figure 1. We suggest that average age differences between supervisors and older subordinates within companies indirectly relate to company performance: the larger the age differences between supervisors and older subordinates, the more frequently employees will experience negative emotions, and, in turn, the lower company performance will be. We further suggest that the indirect linkage depends on whether subordinates express emotions toward their supervisor. If they do, then the linkage unfolds as depicted, but if they suppress their emotions and keep their feelings hidden, the linkage vanishes, rendering the average age-inverse differences in supervisory relationships irrelevant for company performance. In the following paragraphs, we elaborate on this model.

\section{Age-inverse supervisory relationships and negative emotions of subordinates}

Supervisor-subordinate relationships always involve an emotional component (Barsade \& Gibson 2007) and usually feature a mix of positive and negative emotions (Dasborough 2006). In age-inverse supervisory relationships we expect this to be no different. But, in comparison to same-age or older supervisor-younger subordinate relationships, we expect that there will be a higher frequency of negative emotions including anger, fear, and disgust in age-inverse supervisory relationships. These negative emotions are triggered, we posit, by status incongruence and violations of career norms. 


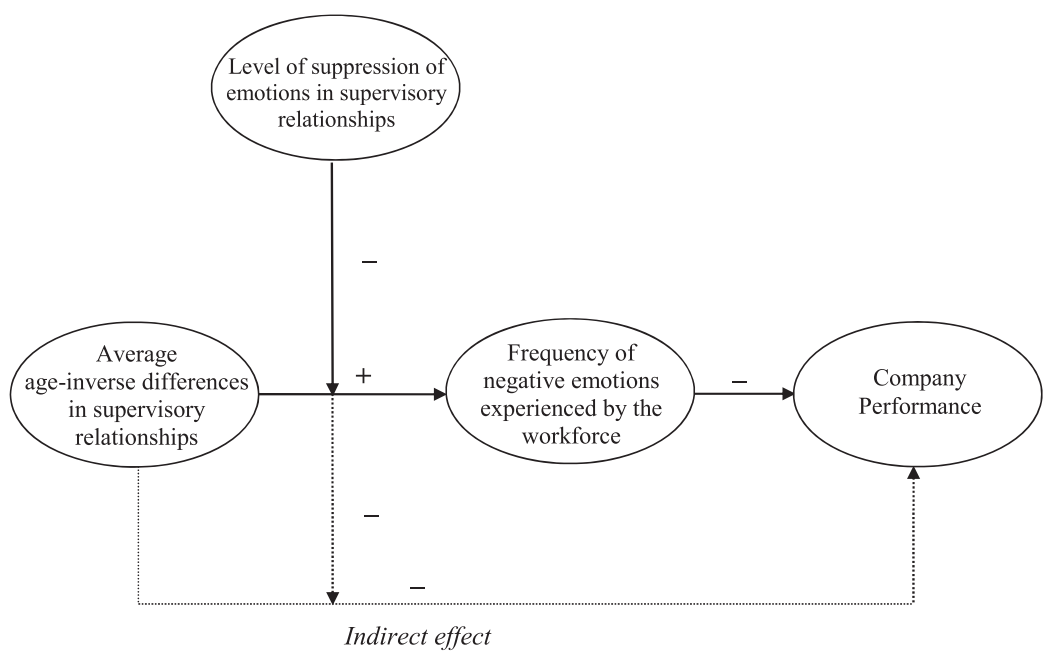

Figure 1. Proposed organizational-level relationships between the average age-inverse differences in supervisory relationships and company performance

The concept of status congruence suggests that age-inverse supervisory relationships tax subordinates emotionally (Hughes 1945; Vecchio 1993). Age is one of several status indicators, including pay, expertise, experience, and hierarchical position. Within groups, status is congruent when the oldest members also receive the highest pay, have the most expertise and the richest experience, and hold the highest hierarchical positions. If, however, age fails to concur with the other status indicators, then statuses are incongruent, evoking unpleasant and potentially upsetting feelings among group members. Age-inverse supervisory relationships, which disassociate age from hierarchical position and prototypical leadership attributes (Buengeler, Homan, \& Voelpel in press), generate status incongruence, causing subordinates to feel negative emotions such as resentment (Cox \& Nkomo 1992) and anger.

Age-inverse supervisory relationships painfully violate career norms. The theory of age grading (Lawrence 1984, 1988) draws from broader social comparison theory (Festinger 1954) to suggest that people judge their career progress by comparing themselves with others of similar age. If they have surpassed others by reaching higher positions, they perceive that they are ahead of schedule. If they have progressed at about the same pace as others of similar age, they are comforted that they are on schedule. However, if they have been promoted more slowly, or if they have failed to rise at all, then they realize that they have fallen behind schedule. When faced with being supervised by a younger person, older employees are forced to recognize their lack of progress (Shore et al. 2003). Working daily under a younger supervisor, older subordinates are constantly reminded that they have failed to keep pace. Those recurring, salient social comparison processes are agonizing: "being off schedule does have a negative impact on people" (Lawrence 1984, p. 24).

Like in other social comparison processes, those perceiving themselves in an inferior position experience negative emotions: people "feel less well off when others fare better" (Frijda 1988: 353). The reason for the negative feelings in the context of inverse age differences is that these differences defy existing and widely held age norms (Lawrence 1984). The "law of comparative feeling" (Frijda 1988: 353) specifies that emotions emerge as result of evaluating oneself in comparison to others within a given frame of reference. Because age norms constitute a frame of reference that places older subordinates of younger supervisors in a position of relative inferiority, negative emotions are likely to ensue in such relationships. And, indeed, scholars have noted that being off schedule elicits adverse feelings about work (Lawrence 1984) including strong emotions such as anxiety and fear (Rosenbaum \& Rubin 1983). Being off schedule can spark emotional crises (Lawrence, 1980) and leave employees less satisfied with their job (Shore et al. 2003).

Status incongruence and violations of career norms, and the negative emotions they evoke, are likely to result in unfavorable treatment of older subordinates by their younger supervisors. In addition to conscious and unconscious 
biases of managers toward older subordinates (e.g., Karpinska, Henkens, \& Schippers 2011; Furunes, Mykletun, \& Solem 2011), research shows that especially in age-inverse supervisory relationships, subordinates receive fewer development opportunities (Shore et al. 2003) and lower promotability ratings (Shore et al. 2003). Supervisors are less likely to communicate with older subordinates than with subordinates of similar age (Zenger \& Lawrence 1989), and like older subordinates less than younger subordinates (Tsui \& O'Reilly 1989). But not all consequences of ageinverse supervisory relationships are negative. One study finds that older subordinates working under younger supervisors tend to be more willing to help coworkers and are less often absent (Perry, Kulik, \& Zhou 1999). This study does not preclude the possibility, though, that these desirable behaviors are responses to negative, rather than neutral or positive, emotions. Indeed, helping behaviors often follow from the experience of shared negative emotion (Rimé 2007). Also, older employees might be afraid to be passed over or feel threatened to lose their job, so they might well be motivated to avoid being absent.

Thus, we build on existing theory and empirical evidence to derive that supervisory relationships in which subordinates are older than their supervisors are likely to evoke more frequent experiences of negative emotions than supervisory relationships in which subordinates are the same age or younger than their supervisors. As the age gap widens, the violation of career norms gets increasingly stronger; thus, the emotional responses should become stronger, too. Older subordinates could still hope to catch up with a supervisor who is just a few years younger; thus, they might not feel so strongly about the inverse age difference. But if the age difference is substantial, the older subordinate will recognize that it will be difficult to overcome the deficit; thus, they are likely to suffer more. Therefore, the greater the age difference between a younger supervisor and an older subordinate, the more painful and negative will be the impact on the subordinate.

\section{Negative emotions spread throughout a company unless suppressed}

Demography and diversity research has long posited that individuals with characteristics that differ from others stand out (Randel 2002) and that these individuals can receive attention throughout an entire organization (Kossek, Markel, \& McHugh 2003). Thus, when a single woman joins an all men team, for example, she stands out and gets noticed far beyond the team, whereas other men joining the team would not receive much attention (Torchia, Calabro, \& Huse 2011). We apply this thinking to relationships, suggesting that relationships that deviate from the norm will stand out and receive attention within an organization. Therefore, age-inverse relationships, because they are against the norm, will be relatively salient to employees within an organization.

Diversity research has shown that the effects of diverse individuals are often brought about by the individuals' salience, rather than by the absolute numbers of such individuals (Randel, 2002). Thus, we suggest that the effects of non-normative relationships depend not so much on how many such relationships exist within an organization, but rather on how much these relationships break with existing norms and thus gain salience. Applied to age-inverse supervisory relationships, this implies that the effects of these relationships are brought about by the extent to which these relationships violate age norms. The higher (rather than the more frequent) the inverse age differences in supervisory relationships, the more salient these relationships will be and thus the more strongly these relationships will affect others in an organization.

Employees pay particular attention to how well salient individuals do and feel (Randel, 2002). Similarly, employees, we suggest, will pay attention to the dynamics of salient non-normative relationships. Thus, employees will take an interest in how the relationship partners in an age-inverse-supervisory relationship feel. If older subordinates express their negative emotions, they signal to others that this type of relationship is problematic (Bartel \& Saavedra 2000) and they may pass on their emotions to others by way of emotion contagion (Barsade, 2002; Elfenbein 2014). Employees in direct proximity to the age-inverse-supervisory relationship may catch the negative emotions and, because of the salience of the relationship, pass them on to others interested in the dynamics of the relationship. According to the emotional broadcaster theory of social sharing (Harber \& Cohen 2005), emotions can thus ripple through large collectivities such as entire organizations. For example, a field study showed that the emotions 33 students 
experienced after a visit to a hospital morgue were shared with 900 people within just 10 days (Harber \& Cohen 2005). Similarly, the negative emotions that employees experience in the context of age-inverse-supervisory relationship likely proliferate, to the extent that they are expressed, to others in the organization through secondary, tertiary, and further sharing. Thus, we suggest that age-inverse-supervisory relationships are among the many sources of emotions at work, and that they tend to evoke emotions-directly, vicariously, or through contagion (Kelly \& Barsade 2001) - that are negative in valence such as anger, fear, and disgust. There is good evidence for the spread of emotions beyond the group level and across large networks (for a recent review, see Menges \& Kilduff 2015).

If older subordinates suppress the expression of their negative emotions, however, they may prevent the spreading of age-related negativity across the company. Emotion suppression involves inhibiting expressions of emotions (Gross 1998). People suppress emotions to regulate their feelings (Koole 2009) and, in social encounters, to avoid personal disclosure (Butler, Gross, Philippot, \& Feldman 2004). Research with individuals showed that emotion suppression, as a self-regulation strategy, has negative consequences such as depression, damaged health, and impaired cognitive performance (Gross 2002). But research involving social interactions also showed that the suppression of emotions can be useful. In teams, for example, emotion suppression focuses employees on tasks rather than on conflicts (Brown, Westbrook, \& Challagalla 2005). Emotion suppression reduces emotional contagion processes and thus stops negativity from spreading (Cole, Walter, \& Bruch 2008), acting as a barrier that prevents negative spillover. Therefore, even though emotion suppression does come at a cost for individuals, it can prove an adaptive emotion regulation strategy for the sake of the collectivity as a whole (Butler et al. 2004; Gross 2013). Here, we extend this thinking to suggest that the suppression of emotions is likely to reduce the spreading of the negative emotions that age inverse supervisory relationships evoke.

The extent to which employees express emotions or engage in emotion suppression depends on the interpersonal context in which they find themselves (Clark 1990; Kilduff, Chiaburu, \& Menges 2010). Organizational environments tend to feature implicit emotion norms that capture the appropriate range of emotions that can be expressed within the organization and toward employees up and down the hierarchy in organizations (Menges Menges \& Kilduff 2015). Some organizations require the expression of specific emotions (Van Maanen \& Kunda 1989), and others tolerate the open expression of a restricted range of emotions (Martin, Knopoff, \& Beckman 1998). During their socialization in a company, employees develop a generalized sense as to whether, to what extent, and to whom it is acceptable and appropriate to express emotions within their given organizational environment ( $\mathrm{O}$ 'Reilly \& Chatman 1996). As a result, employees individually adjust their emotion expression to fit in with the general organizational norm. But because emotion norms apply across a workforce (Mann 1999), employees, despite individual differences, are likely to converge on relatively similar levels of emotion suppression while at work. Thus, some organizations are likely to feature higher levels of emotion suppression in interactions with supervisors than others.

Therefore, we expect the effect of age-inverse supervisory relationships on employees' emotions to depend on the extent to which employees express or suppress emotions. The negative emotions that emerge in age-inverse supervisory relationships are likely to spread across a workforce, unless suppressed, thus raising the overall level of negative emotional experiences among employees within an organization. We hypothesize:

Hypothesis 1: The association between the average age-inverse differences in supervisory relationships in a company and the negative emotions experienced by employees throughout a company depends on the extent to which subordinates suppress the expression of emotions toward their supervisor. The association is significant and positive for low levels of subordinates' emotion suppression, but not significant for high levels of subordinates' emotion suppression.

\section{High frequencies of negative emotions hamper company performance}

The association between the average age-inverse differences in supervisory relationships and the frequency of negative emotions at the organizational level is threatening because negative emotions hinder collaboration (Yang \& 
Mossholder 2004), deteriorate work motivation (Seo, Barrett, \& Bartunek 2004), deflect attention from purposeful goal-pursuits to coping attempts (Brown et al. 2005; Lazarus 1991), harm productivity, and lower performance (Brown et al. 2005; Cole et al. 2008; Kiefer 2005). If team members share negative emotions, the entire team's performance is damaged (Cole et al. 2008; Losada \& Heaphy 2004). But negative emotions are not always bad for performance: a meta-analysis review points out that negative group emotions can enhance performance if these emotions are because of a cause that is external to the group or if the group convenes only once, but diminishes performance if these emotions are because of a group-intrinsic cause or if the group convenes regularly (Knight \& Eisenkraft 2014).

There is no research, to our knowledge, that links employees' negative emotions to performance at the organizational level. Earlier findings suggest that the workforce is among the most important factors driving company performance (Huselid 1995). Therefore, we propose that the emotions shared within the workforce likely affect company performance. Age-inverse supervisory relationships are a trigger for negative emotions that resides within the company, and the employees sharing those negative emotions work together over extended periods of time. Therefore, in line with the meta-analytical evidence described above (Knight \& Eisenkraft 2014), we propose that frequent negative emotions among employees are likely to weaken company performance. A workforce tuned to negativity is likely to show deteriorated collective efforts that translate into overall impaired company performance, bringing us to hypothesize:

Hypothesis 2: The frequency of negative emotions that employees experience is negatively associated with the company's performance.

\section{Age-inverse supervisory relationships are indirectly linked to company performance}

Combining the links thus far established, we conclude that age differences between younger supervisors and older subordinates are likely to relate indirectly to company performance through how frequently negative emotions occur. In companies that have large age differences between supervisors and older subordinates, employees experience negative emotions such as anger, fear, and disgust more frequently than in companies that have smaller or no age differences between supervisors and older subordinates. However, the linkage of age-inverse supervisory relationships, company performance, and frequency of negative emotions depends on whether subordinates tend to express or suppress emotions: the linkage vanishes if subordinates keep their emotions to themselves. Thus, we hypothesize:

Hypothesis 3: The average age-inverse difference in supervisory relationships is positively associated with the frequency of employees' negative emotions, which then is negatively associated with company performance. The indirect association occurs for low levels of emotion suppression, but not for high levels of emotion suppression.

\section{Methods}

\section{Sample and procedure}

The level of analysis for this study is the company-level and thus we collected data from multiple companies. A professional benchmarking agency helped us recruit 110 companies to participate in this study through a media campaign that involved mainly print advertisements and direct mailing. As selection criteria, the agency specified that the companies had to have their headquarters in Germany and have workforces of fewer than 5000 employees. The companies thus recruited voluntary agreed to participate in our research and were offered a benchmarking report in return for their participation. Out of the 110 companies that had initially agreed to participate, 61 provided 
sufficient data on the focal variables of this study (organizational level response rate: 56 percent). The size of these companies ranged from 18 to 3265 employees, with a mean of 357 employees, and represented a wide range of industries, including services (65 percent), manufacturing (20 percent), trade (10 percent), and finance and insurance (6 percent).

We collected data from four different data sources. First, all employees were invited to participate in this study through an e-mail sent by the respective company's HR department. The e-mail provided a short description of the study and a link to a survey website that was hosted by an independent IT company. All employees answered demographic questions including their age and the age of their supervisor. Additionally, an algorithm programmed into the website randomly selected 25 percent of the employees to answered questions about the frequency of employees' negative emotions (data source one). Another 25 percent of employees were randomly selected to answer questions assessing the tendency to suppress emotions toward the supervisor (data source two). This selection mechanism was installed to lower the number of questions that each employee had to answer and thus to increase the response rate. Altogether, 7802 employees provided complete responses. The average within-organization response rate was 75 percent $(S D=30$ percent). Responding employees were relatively balanced between men (53 percent) and women (47 percent) and averaged 38 years of age $(S D=4.6)$.

Furthermore, we invited the members of the top management team of each company to participate in this study, again through an e-mail sent by the HR department. The e-mail contained a short description of the study and a link to an independent website with a survey about company performance (data source three). In 20 of the companies, one top management team member responded. For the other companies, as many as 12 members of the top management team participated. In total, 175 top management team members responded, yielding an average withinorganization response rate of 63 percent $(S D=30)$. Respondents averaged 46 years old and were mostly men ( 86 percent). Finally, we asked the $61 \mathrm{HR}$ directors of the participating companies to complete a web-based questionnaire to capture several control variables (data source four).

This multiple-respondent design with four different data sources prevented common source bias, a form of common method variance (Podsakoff, MacKenzie, \& Podsakoff 2012). In this study, all self-reported measures (i.e., frequency of negative emotions experienced by the workforce, level of suppression of emotions in supervisory relationships, and company performance) were collected from different data sources. Thus, the data obtained were not affected by common source bias. In addition, because age is an objective demographic variable, the measurement of age was unlikely to be biased because of common method variance.

\section{Measures}

Our study focused on the organizational level, and so all constructs measured through individual responses were aggregated to the organizational level. To examine the adequacy of the aggregation, we followed the advice by LeBreton and Senter (2007). We calculated several statistical indicators to assess both inter-rater agreement (IRA) and inter-rater reliability (IRR). Specifically, we report $\mathrm{AD}_{M(J)}$ (Burke, Finkelstein, \& Dusig 1999) and $\mathrm{r}_{\mathrm{wg}(\mathrm{j})}(\mathrm{James}$, Demaree, \& Wolf 1984) to address IRA, and we report two intra-class correlation coefficients $\left(\mathrm{ICC}_{1}\right.$ and $\mathrm{ICC}_{2}$; Bliese 2000) to report both IRR and IRA.

\section{The average age-inverse differences in supervisory relationships}

We assessed age-inverse supervisory relationships by asking subordinates their age and the age of their direct supervisor in the employee survey. Difference scores were calculated by subtracting each supervisor's age from the subordinate's age (Perry \& Finkelstein 1999; Tsui \& O'Reilly 1989; Tsui, Porter, \& Egan 2002). If the difference score was positive, the supervisor was younger than the subordinate. To form one score per company for the average ageinverse differences in supervisory relationships, we averaged the positive age differences per company. Difference scores that were negative (i.e., age-consistent supervisory differences) were not considered here (but were used as a control variable-see below). We examined whether companies systematically differed in the extent to which they 
featured age-inverse supervisory relationships. We calculated ICC values based on a one-way ANOVA $\left(\right.$ ICC $_{1}=.04$, $\mathrm{F}$ [2.47], $p<.001 ; \mathrm{ICC}_{2}=.60$ ). The significant result suggests that there were significant differences between organizations in the extent to which age-inverse supervisory relationships were common. We also checked whether the number of age-inverse supervisory relationships outweighed the number of traditional supervisory relationships in any of the participating organizations. This was only the case in one of the 61 companies (the average percentage of such relationships across companies was 27 percent) thus supporting the view that such relationships gain salience because they are in the minority (Kanter, 1977; Kossek et al. 2003; Randel 2002).

\section{The frequency of negative emotions experienced by the workforce}

We measured the frequency with which employees experience negative emotions in the employee survey, based on responses from a randomly selected sample of 25 percent of employees. Emotions were measured at the organizational level (i.e., level of the workforce), because group emotion research indicates that emotions are shared at the collective level through the social interaction of employees (Barsade \& Knight 2015; Menges \& Kilduff 2015). In line with previous research (e.g., Menges, Walter, Vogel, \& Bruch 2011), we therefore assessed the frequency of negative emotions experienced by the workforce based on a referent-shift consensus model (Chan 1998), asking participants how frequently the employees of their company experienced the following exemplary negative higharousal emotions within the last six months: angry, furious, frightened, and disgusted. These items were taken from the job-related affective well-being scale (JAWS; Van Katwyk, Fox, Spector, \& Kelloway 2000), and selected because their intensity will likely make such emotional experienes salient across the workforce. Participants responded on a five-point scale, ranging from 1 (never) to 5 (extremely often/always). The responses were averaged and aggregated to the organizational level to obtain an overall score per company. Four different aggregation indices showed that the aggregation of the data to the organizational level of analysis was justified $\left(\mathrm{ICC}_{1}=.14, \mathrm{~F}\right.$ [5.92], $p<.001$; $\mathrm{ICC}_{2}=.82$; mean $\mathrm{AD}_{M(J)}=.83$; mean $\left.\mathrm{r}_{\mathrm{wg}(\mathrm{j})}=.92\right)$. The $\mathrm{r}_{\mathrm{wg}(\mathrm{j})}$ index of .92 demonstrated very strong agreement within organizations (LeBreton \& Senter 2007), and the $\mathrm{ICC}_{1}$ effect size of .14 indicated medium to strong organizationallevel effects (LeBreton \& Senter 2007). The internal consistency estimate was good $(\alpha=.90)$.

\section{The level of suppression of emotions in supervisory relationships}

We assessed the extent to which subordinates express or suppress emotions toward their supervisor in the employee survey version, based on responses from a randomly selected sample of 25 percent of employees. (This sample did not overlap with the sample of employees who had answered questions concerning the frequency of negative emotions.) Emotion suppression was measured at the individual level (i.e., level of the employee), because emotion regulation research indicates that suppression is an inherently intrapersonal process through which individuals seek to control their emotion expression and align their expression with social expectations (Butler et al. 2004). To the extent that many employees of a company engage similarly in the suppression of emotion, emotion suppression is a characteristic of the company as a whole (Menges \& Kilduff 2015). In light of these considerations, we measured the level of suppression of emotions in supervisory relationships based on a direct consensus model (Chan 1998), asking participants to reply to four questions concerning the extent to which they convey emotions to their supervisor. The items were adapted from a widely used measure of emotion suppression (Gross \& John 2003); a sample item is, "If I have negative emotions, I don't show them toward my supervisor." Participants indicated how well the items described them on a seven-point scale from 1 (strongly disagree) to 7 (strongly agree). Aggregation statistics $\left(I C C_{1}=.04, \mathrm{~F}[2.13], p<0.001 ; I C C_{2}=.53\right.$; mean $\mathrm{AD}_{M(J)}=.67$, mean $\left.\mathrm{r}_{\mathrm{wg}(\mathrm{j})}=.80\right)$ showed that employees within a company were more similar to each other in their suppression tendencies than employees of different companies. The $\mathrm{r}_{\mathrm{wg}(\mathrm{j})}$ index of .80 indicated strong IRA (LeBreton \& Senter 2007), and the $\mathrm{ICC}_{1}$ of .04 pointed toward effect sizes that were small, but appropriate for organizational-level analysis (LeBreton \& Senter 2007). Therefore, we averaged and aggregated the individual responses to the organizational level. The internal consistency was good $(\alpha=.81)$. 


\section{Company performance}

The information about company performance was obtained from top management team members. In line with prior recommendations (Combs, Crook, \& Shook 2005), we constructed our measure by considering operational and organizational performance as two distinct dimensions that form one overall company performance construct (Kunze et al. 2011). Operational performance was assessed using the items employee productivity and efficiency of business procedures. Organizational performance was gauged with items on financial performance, company growth, and return on assets. We asked the top management team members to rate their company's performance in the current year relative to the performance of their main competitors within the same industry and in the same region. This approach is in line with many other studies involving a diverse sample of companies (Delaney \& Huselid 1996; Wall et al. 2004). For companies with more than one top management team member responding, the top management team members converged in their ratings of their company's performance, as indicated by adequate agreement statistics $\left(I C C_{1}=.32, \mathrm{~F}[2.68] p<0.001 ; I_{C} C_{2}=.63 ;\right.$ mean $\left.\mathrm{r}_{\mathrm{wg}(\mathrm{j})}=.85\right)$. The performance measure also yielded adequate internal consistency $(\alpha=.91)$. Finally, to account for the two-dimensional structure of the performance construct and to economize the degrees of freedom (Williams \& O'Boyle 2008), we parceled the items for each of the two dimensions. The two item parcels formed the indicators for the latent construct company performance.

\section{Control variables}

A number of additional factors might influence our study variables and thus needed to be included in our analyses to avoid spurious results. First, to account for the alternative explanation that not only age-inverse but also ageconsistent leadership age differences are related to emotional states in organizations, we controlled for the average age-consistent differences in supervisory relationships by averaging all supervisor-subordinate differences in which the supervisor was older than the subordinate. To better compare and discuss the effects of the age-inverse and ageconsistent differences, we transformed the age-consistent differences into positive values before aggregating them to the organizational level. Second, we controlled for the percentage of age-inverse supervisory relationships per company to eliminate the alternative hypothesis that the relative number of age-inverse differences rather than the average age-inverse differences affect the frequency of negative emotions. Third, we controlled for the mean age of the employees within the companies because research at the individual level shows that older adults are generally happier than younger adults (Mroczek \& Kolarz 1998), a tendency that could influence the frequency of negative emotions as well as company performance. Fourth, following many studies on relational age differences (Perry et al. 1999; Tsui \& O'Reilly 1989) we controlled for the mean age of supervisors per company. Finally, besides age we also took the average organizational tenure of the participating employees as a control variable into account.

Apart from those age-related control variables, we also considered variables that could confound the effects at the organizational level. First, because performance levels may vary systematically between different industries, we controlled for companies' affiliation with one of four categories: services, manufacturing, finance and insurance, and trade. Second, company size is related to various employee attitudes and behaviors as well as performance and thus needs to be controlled (Pierce \& Gardner 2004). We measured company size as the number of employees and $\log$ transformed this measure to account for its skewed distribution. Third, as prior studies have recommended for organizational-level relationships (Delaney \& Huselid 1996; Tsai 2001), we included market competition ("How strong is the competitive pressure your organization experiences?"; $1=$ extremely low, $7=$ extremely high), reported by the heads of human resources, as a covariate in our analyses to control for a potential influence of this factor on company performance. Fourth, we controlled for the percentage of unionization within the companies, given that other organizational research has proposed union coverage to be relevant for organizational performance (Delaney $\&$ Huselid 1996). Fifth, we entered the average response rate per company in our model to control for potential nonresponse biases. Finally, we also controlled for the companies' performance in the previous year of the survey [company performance $(\mathrm{t}-1)]$. For that purpose we asked the HR representative to assess the performance on the same five items as for the performance measure for the current year (i.e., company performance). To reduce model complexity, we averaged the five performance items to form one manifest variable. 


\section{Analysis}

The proposed hypotheses were tested within structural equation models (SEM), using the statistical software package Amos 18, and the two-step approach suggested by Anderson and Gerbing (1988), investigating first the measurement model and subsequently the structural model. To secure the adequacy of our model fit, we inspected three fit statistics: the root mean square error of approximation (RMSEA) index in combination with two incremental fit indices; the comparative fit index (CFI) and the incremental fit index (IFI) (Bentler 2007). We used conventional cut-off points for these indices: $>.90$ for the comparative fit indices (CFI and IFI) and <.08 for the RMSEA (Hu \& Bentler 1999). To compare different model solutions, we used the Akaike information criterion (AIC) (Akaike 1987): the best model solution has the lowest AIC value.

Our hypotheses included both moderation and indirect effects. First, to test for the moderation effects, we followed the procedure described by Little, Bovaird, and Widaman (2006) and used orthogonal-centered product terms of the manifest constructs of emotion suppression and age-inverse supervisory differences. To ease the interpretation, we also graphically plotted the interaction results and performed simple slope tests (Aiken \& West 1991). Second, we tested the indirect effects using bootstrapping procedures, following the recommendations by James, Mulaik, and Brett (2006) and Cheung and Lau (2008). In line with the procedure for regression analyses described by Preacher, Rucker, and Hayes (2007), we specified two models in SEM with high values of the moderator $(+1$ standard deviation) and low values of the moderator ( -1 standard deviation) to inspect the conditional indirect effects in the moderated-mediation model.

\section{Results}

Table 1 summarizes means, standard deviations, and correlations for all study variables. Among the focal study variables, we detected several correlations. The average age-inverse difference in supervisory relationships was significantly and positively related to the frequency of negative emotions $(r=.45, p<.001)$. The frequency of negative emotions was negatively related to company performance $(r=-.33, p<.010)$. Emotion suppression was positively related to the frequency of negative emotions $(r=.26, p<.05)$, leaving some room for an alternative model solution, which we will test later. Among the focal study variables and the control variables, we also found several correlations. For example, mean age positively related to frequency of negative emotions $(r=.37, p<.01)$, indicating that as the workforce ages, negative feelings within companies might increase. Also two of the industry dummies (production and service) were significantly related to the average age-inverse differences in supervisory relationshipsan observation that we will return to in the discussion section.

Upon inspection of the bivariate correlation, we followed the recommendations by Becker (2005) and kept only those five control variables in the further analysis that showed significant correlations with the two outcome measures-frequency of negative emotions and performance. These control variables were company performance $(\mathrm{t}-1)$, company size, mean age of subordinates, mean tenure of subordinates mean age of supervisors, response rate, and unionization rate. This allowed us to have more stable SEM estimates through a better parameter/sample size ratio.

\section{Measurement model}

The measurement model consists of one manifest construct (i.e., the average age-inverse differences in supervisory relationships) and three latent constructs (i.e., emotion suppression, frequency of negative emotions, and company performance). The overall model fit for the simultaneous CFA for all model constructs revealed satisfactory results $\left(\chi^{2}=51, d f=41, n s ; \mathrm{CFI}=.97, \mathrm{IFI}=.97, \mathrm{RMSEA}=.06, \mathrm{AIC}=124\right)$, with all indices falling within the range of a good model fit. In addition, none of the factor loadings for each construct was under 0.50 - a threshold often applied in 


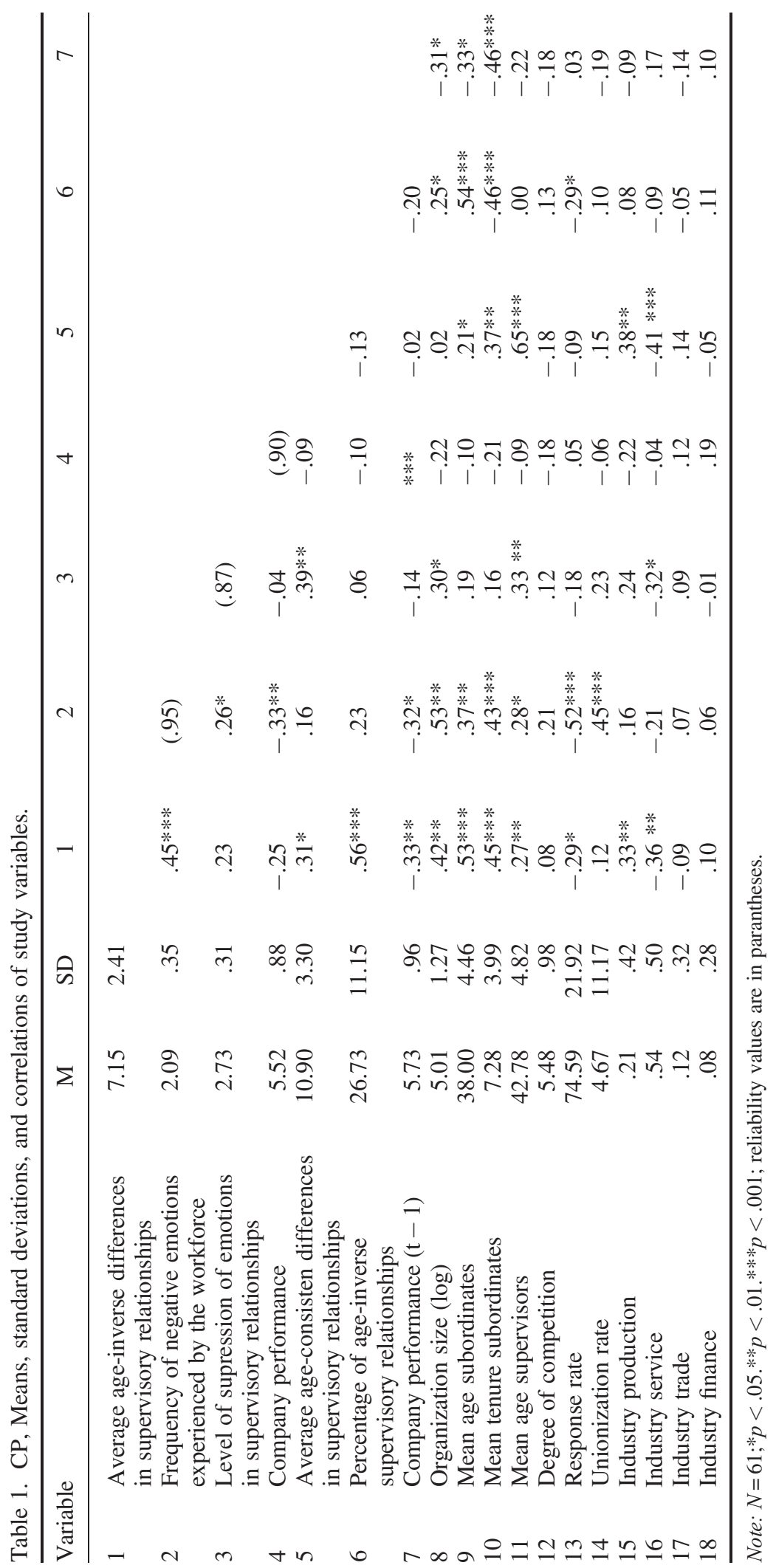




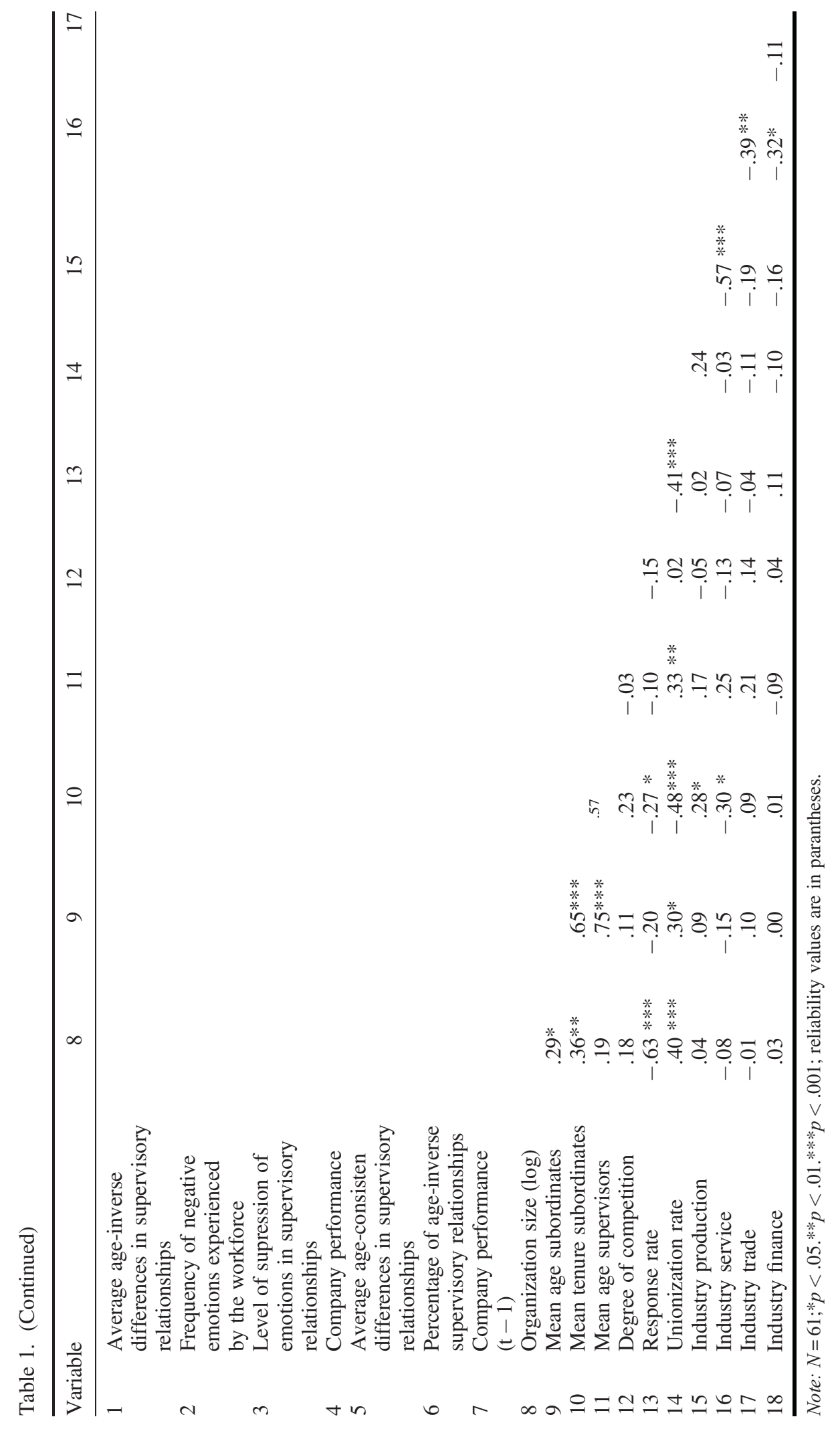


factor analysis to evaluate the fit of latent constructs to their respective indicators (Hulland 1999) (see Figure 1). To check the discriminative validity of our constructs, we computed three alternative models, one with emotion suppression and the frequency of negative emotions loading on one common factor (alternative model 1), a second assuming all independent measures (age-inverse difference scores, frequency of negative emotions, emotion suppression) loading on one common factor (alternative model 2), and a third specifying a common factor for all study items (alternative model 3). As Table 2 shows, our measurement model had a substantially better fit than these alternative models.

\section{Structural model}

In the second step of our analysis we examined the structural paths in our specified model. As Figure 1 shows, we hypothesized that (i) age difference scores would relate to the frequency of negative emotions at varying strength depending on subordinates' suppression of negative emotion toward supervisors (Hypothesis 1); (ii) the frequency of negative emotions would directly relate to the company's performance (Hypothesis 2); and (iii) the age differences would indirectly relate to performance through the frequency of negative emotions, depending on subordinates' suppression of negative emotion toward supervisors (Hypothesis 3). Paths from all included control variables and from emotion suppression to the dependent constructs were included in our specified structural model (Richardson \& Vandenberg 2005).

We tested all hypotheses simultaneously in a moderated-mediation model (see Figure 2). The overall fit statistics of the model were supportive $\left(\chi^{2}=103, d f=97, n s ; \mathrm{CFI}=.99, \mathrm{IFI}=.99\right.$, RMSEA $=.03$, AIC $\left.=327\right)$. The moderatedmediation model indicated that the age-inverse difference scores were significantly related to the frequency of negative emotions ( $\beta=.30, t=2.33, p<.05$ ). Furthermore, the interaction term of the age difference scores and the emotion suppression scores was significantly related with the frequency of negative emotions $(\beta=-.24, t=-2.29, p<.05)$, suggesting, in line with Hypothesis 1, that the association between average age-inverse differences in supervisory relationships in a company and the frequency of negative emotions experienced by employees throughout a company depends on the extent to which subordinates suppress the expression of emotions toward their supervisor. To further examine whether this association holds for low levels of subordinates' expressive suppression, but not for high levels of subordinates' expressive suppression, as Hypothesis 1 specifies, we conducted conventional graphical analyses (Aiken \& West 1991) and plotted the simple slopes, applying results from regression analyses at one standard deviation above and below the mean of emotion suppression (see Figure 2). As expected, higher levels of emotion suppression buffered the relation of age-inverse differences on negative affective climate. Under conditions of high emotion suppression, the association between age-inverse differences and the frequency of negative emotions was non-significant (simple slope $=.06, t=.31, \mathrm{~ns}$ ), whereas under conditions of low emotion suppression we observed a significant positive association (simple slope $=.71, t=2.84, p<.01$ ). These findings supported Hypothesis 1 . Furthermore, as expected, the frequency of negative emotions was negatively associated with company performance $(\beta=-.34, t=-1.78, p<.05)$, supporting Hypothesis 2. An inspection of effect sizes showed that our model explained 56 percent of the variance in the frequency of negative emotions and 28 percent of the variance in company performance.

We examined whether the indirect relationship between the age-inverse difference scores and company performance mediated by the frequency of negative emotions was conditional on the level of emotion suppression within the companies, as suggested in Hypothesis 3. Applying bootstrapping procedures (Cheung \& Lau 2008) we tested for the significance of the indirect effects between the age-inverse difference scores and performance under different values of emotion suppression. The indirect relation in the moderated-mediation model (e.g., under mean values of emotion suppression) was negative and significant $(\beta=-.10$, with a 90 percent bias corrected confidence interval (BCCI) $[-.361,-.001])$. Under conditions of high emotion suppression (+1SD) the indirect relation was found to be non-significant $(\beta=.00$, BCCI $[-.163, .154])$, but under conditions of low emotion suppression ( $-1 \mathrm{SD})$ the indirect relation was strongly negative and significant $(\beta=-.20$, BCCI $[-.668,-.004])$. These results provided evidence that emotion suppression buffered the indirect negative relation between age-inverse differences and performance and supported Hypothesis 3. 
Table 2. Measurement model comparison.

\begin{tabular}{|c|c|c|c|c|c|c|c|c|c|}
\hline Model & $\chi^{2}$ & df & $\chi^{2 / \mathrm{df}}$ & $\Delta \chi^{2}$ & $\Delta \mathrm{df}$ & CFI & IFI & RMSEA & AIC \\
\hline Hypothesized model & 51 & 41 & 1.24 & & & .97 & .97 & .06 & 124 \\
\hline $\begin{array}{l}\text { Alternative model 1: experience of } \\
\text { negative emotions and suppression } \\
\text { toward supervisor one factor }\end{array}$ & 141 & 43 & 3.28 & $90 *$ & 2 & .70 & .71 & .19 & 209 \\
\hline $\begin{array}{l}\text { Alternative model 2: all independent } \\
\text { variables one factor }\end{array}$ & 141 & 43 & 3.28 & $90 *$ & 2 & .70 & .71 & .19 & 209 \\
\hline Alternative model 3: one common factor & 178 & 44 & 4.05 & $127 *$ & -3 & .59 & .61 & .17 & 244 \\
\hline
\end{tabular}

Note: $N=61 ; \mathrm{CFI}=$ Comparative fit index; $\mathrm{IFI}=$ Incremental fit index; RMSEA = Root Mean Square Error of Approximation. The two alternative measurement models are compared with the hypothesized model.

$*=$ chi-difference statistic $p<.05$ compared with the hypothesized model. The lowest Akaike information criterion (AIC) value shows the best fitting model.

\section{Alternative models}

To inspect the robustness of our results, we examined whether the relationship between average age-inverse differences in supervisory relationships in a company and negative emotions was non-linear. This was not the case. We also compared the hypothesized moderated-mediation model with nine alternative models, with none showing a significantly better fit (see Table 3). First in a no-controls model (alternative model 1), all hypothesized effects remained significant and in the expected direction. Therefore, the control variables did not bias our results (Becker 2005). Models with other alternative path configurations or further variables also did not yield better results than the hypothesized moderated-mediation model. Specifically, the hypothesized moderated-mediation model was more parsimonious than the a performance-only model (alternative model 2), in which the direct-effects of age-inverse relationships allowed direct paths between the age-difference score and performance; a mediation-only model (alternative model 3), in which indirect paths between the age-difference scores and company performance were transmitted through the frequency of negative emotions, while the moderating path was set to zero; a moderation-only model (alternative model 4), in which paths existed both from the age-difference scores and from the moderator term to the frequency of negative emotions, while the path from the frequency of negative emotions to company performance was set to zero; and a double-moderation model (alternative model 5) that resembled the moderated-mediation model but included additional direct paths from the age-difference score and the emotion-suppression moderator term to company performance. Furthermore the moderated-mediation model was more parsimonious than an allcontrols model (alternative model 6 ) that included all control variables from the correlation analysis. In this model all hypothesized relationships remained significant on a 5 percent level indicating that the proposed effects were robust when controlling for the insignificant control variables. The moderated-mediation model was also more parsimonious than an age-consistent relationships/suppression moderation model (alternative model 7), in which ageconsistent supervisory differences were added as a further control variable and integrated in a moderation of emotion suppression on the relationship between age-consistent differences and the frequency of negative emotions. The main effect of age-consistent supervisory differences and the second moderator were non-significant, ruling out the alternative hypotheses that high emotion suppression might be helpful for both age-consistent and age-inverse differences between supervisors and subordinates. Furthermore we also controlled for the alternative hypotheses that the age-inverse supervisory relationships might be relevant only in companies with a high percentage of such relationships, by specifying a percentage of age-inverse relationships moderation model (alternative model 8) with the percentage of age-inverse supervisory relationships relating to the frequency of negative emotion expression and an additional moderation term of the average age-inverse relationships with the percentage of age-inverse relationships. This model was less parsimonious than the hypothesized moderated-mediation model, and both the main effect of percentage of age-inverse difference scores and the moderation effect were non-significant indicating that it was 


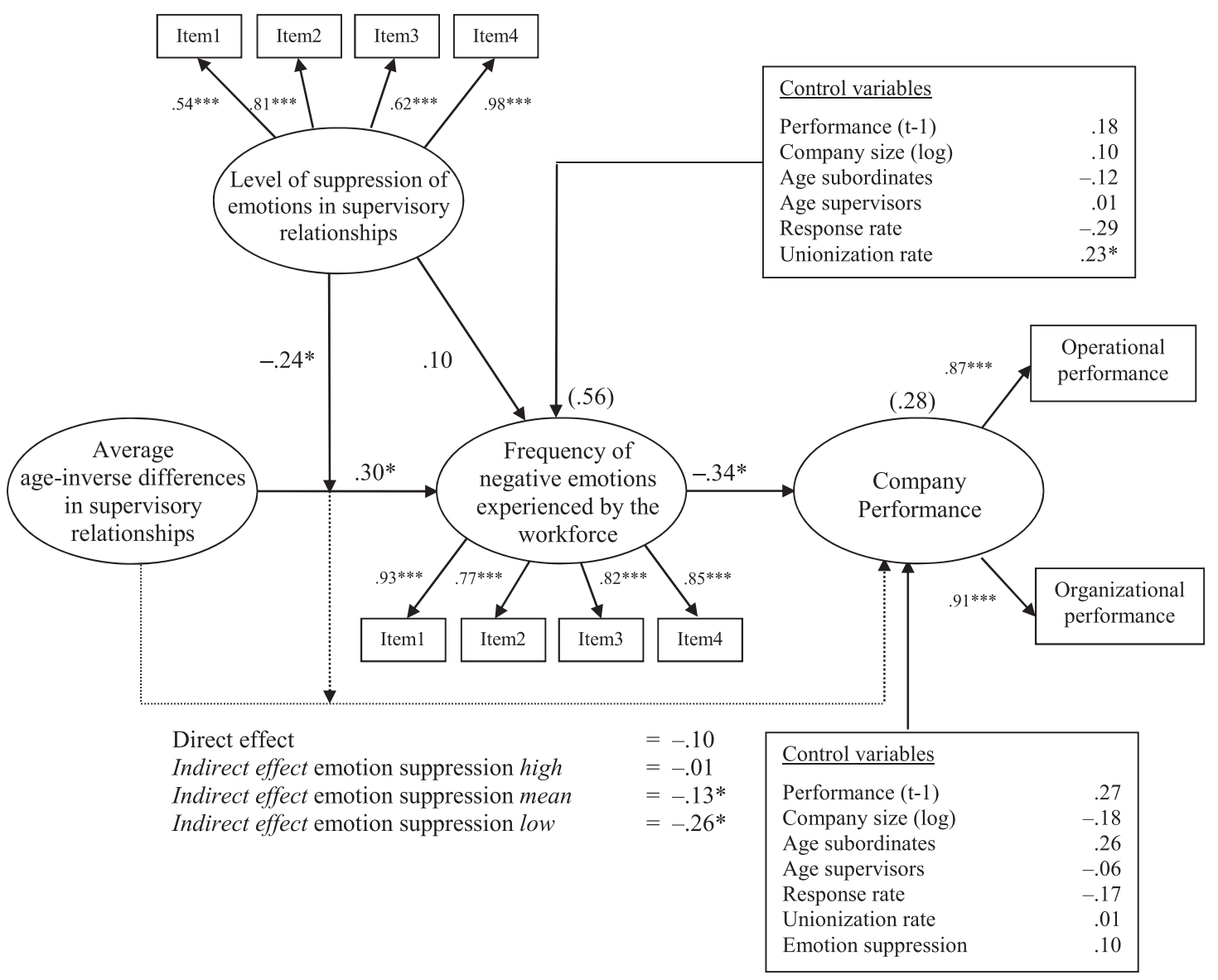

Note. $N=61$ companies, ${ }^{*} p<.05, * * p<.01, * * * p<.001$ (one-sided), squared multiple correlations in parentheses. For calculating the indirect effects 3,000 bootstrap samples were used.

Figure 2. Results of the moderated-mediation model of the average age-inverse supervisory relationships on company performance

indeed the average strength of age-inverse supervisory relationships that was driving the results. Inspired by the results from the bivariate correlations we also tested an age differences to emotion suppression to negative emotions model (alternative model 9), which assumed an indirect mediation route from the age-inverse difference scores via emotion suppression to the frequency of negative emotions and ultimately also to performance, while the moderator effect was set to zero. This model had a significantly worse fit compared with the moderated-indirect model, thus ruling out the alternative explanation that emotion suppression norms mediate the path from age-inverse relational differences to company performance. Furthermore, because the study design was cross-sectional, causal orderings other than the hypothesized model are possible. Even though statistical tests cannot fully resolve this issue (Mathieu \& Taylor 2006), we took several steps to gain greater confidence in the implied causality of our model. First, we examined a model of reverse causality (i.e., the horizontal arrows in Figure 1 pointing in the opposite direction). In this alternative model the effect of performance on frequencies of negative emotions $(\beta=-.11, t=-1.20, n s)$ was not significant, while the effect of frequencies of negative emotions on age-inverse supervisory relationships $(\beta=-.24, t=-1.74, p<.05)$ was significant, but weaker. Furthermore in this alternative model there was no moderating effect of emotion suppression $(\beta=-.13, t=-1.23, n s)$ and no indirect effect of company performance via frequency of negative emotions on age-inverse supervisory relationships. These results support the hypothesized ordering and assumed direction of effects. 
Table 3. Structural model comparison.

\begin{tabular}{|c|c|c|c|c|c|c|c|c|c|}
\hline Model & $\chi^{2}$ & df & $\begin{array}{l}\chi^{2 /} \\
\text { df }\end{array}$ & $\Delta \chi^{2}$ & $\Delta \mathrm{df}$ & CFI & IFI & RMSEA & AIC \\
\hline $\begin{array}{l}\text { Hypothesized model: moderated-mediation } \\
\text { model }\end{array}$ & 103 & 97 & 1.06 & & & 99 & 99 & .03 & 327 \\
\hline \multicolumn{10}{|l|}{ Nested models } \\
\hline Alternative model 1: No-controls model & 111 & 94 & 1.18 & $8^{*}$ & 3 & .97 & .96 & .06 & 229 \\
\hline Alternative model 2: performance-only model & 111 & 99 & 1.12 & $8^{*}$ & 2 & .98 & .98 & .05 & 331 \\
\hline Alternative model 3: mediation-only model & 108 & 98 & 1.10 & $5^{*}$ & 1 & .98 & .98 & .04 & 330 \\
\hline Alternative model 4: moderation-only model & 108 & 98 & 1.10 & $5^{*}$ & 1 & .98 & .98 & .04 & 330 \\
\hline $\begin{array}{l}\text { Alternative model 4: double-moderation } \\
\text { model }\end{array}$ & 103 & 96 & 1.07 & $0^{+}$ & 1 & .99 & .99 & .04 & 329 \\
\hline \multicolumn{10}{|l|}{ Non-nested models } \\
\hline 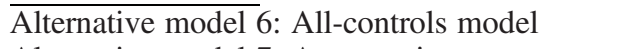 & 227 & 147 & 1.54 & $116^{* * * *}$ & 48 & .91 & .93 & .10 & 635 \\
\hline $\begin{array}{l}\text { Alternative model 7: Age-consistent } \\
\text { relationships/suppression moderation }\end{array}$ & 119 & 106 & 1.12 & $16^{+}$ & 9 & .98 & .98 & .04 & 368 \\
\hline $\begin{array}{l}\text { Alternative model 8: Percentage of age- } \\
\text { inverse relationships moderation }\end{array}$ & 136 & 105 & 1.30 & $25^{* *}$ & 6 & .95 & .96 & .07 & 388 \\
\hline $\begin{array}{l}\text { Alternative model 9: Age differences- } \\
\text { suppression-negative affect model }\end{array}$ & 110 & 101 & 1.09 & $7^{+}$ & 4 & .98 & .98 & .04 & 288 \\
\hline
\end{tabular}

Note: $N=61$; CFI = Comparative fit index; IFI = Incremental Fit Index; RMSEA = Root Mean Square Error of Approximation. The nine alternative models are compared the moderated-mediation model 1 .

$*=$ chi-difference statistic $p<.05$ compared to the moderated mediation model.

${ }^{+}$indicates that the model is less parsimonious than the moderated indirect-effects model. The lowest Akaike Information Criterion (AIC) value shows the best fitting model.

Second, we assessed whether our model was affected by an endogeneity bias (Antonakis, Bendahan, Jacquart, \& Lalive 2010). If endogeneity can be ruled out, the implied flow of causality is statistically supported (Antonakis et al. 2010). An endogeneity bias arises from an unmeasured omitted variable that might be related to the error term of both the independent and the dependent variables. To examine endogeneity, we followed the procedure described by Shaver (2005) for mediation analyses, and specified two additional models. First was an alternative model allowing an error correlation between age-inverse differences and frequency of negative emotions and using average ageconsistent differences, percentage of age-inverse differences, service and production industry dummies as instruments, as they showed high correlations with age-inverse differences and no significant correlation with the frequency of negative emotions. In this alternative model the error correlation was non-significant, and the relationship between age-inverse age-differences and frequency of negative emotions remained positive and significant $(\beta=.58, t=6.18$, $p<.001)$. Second was an alternative model allowing error correlations between frequency of negative emotions and performance, while using mean age of the subordinates, mean age of the supervisors, response rate, and unionization rate as instruments, as they show a high correlation with frequency of negative emotions and no significant correlation with performance. The error correlation was non-significant and the relationship between frequencies of negative emotions remained negative and significant at a 10 percent level $(\beta=-.33, t=-1.86, p<.10)$. In sum these results indicate that our effects are robust, even when controlling for a potential endogeneity bias.

\section{Discussion}

Age differences are a universal aspect of human relationships. Whenever people come together, they unconsciously and automatically assess each other's age and adapt their behavior accordingly. Age has historically been closely tied to hierarchical status (Linton 1936); older individuals were granted leadership positions because of the 
knowledge and wisdom which were expected to come with age. More recently, however, perceptions of age have shifted toward an increased appreciation of youth as a source of fresh and innovative leadership. As a result, many companies have shifted from seniority-based to merit-based promotion systems (Chiang \& Birtch 2007). In conjunction with demographic developments (Peeters \& Groot 2012), those changes mean that supervisors are no longer necessarily older workers. On the contrary, many organizations have reversed the traditional relational age structure so that supervisors are often younger than their subordinates (Cappeli \& Novelli 2010).

In this study we examined the effects of those changes, thus addressing a puzzle in our understanding of the effects that organizational age structure has on workforce emotions and company performance. We asked whether companies, by neglecting age differences, reap alleged emotional and performance benefits or, as relational demography theories (i.e., Tsui \& O’Reilly 1989) suggest, suffer adverse consequences. Based on our theorizing and an empirical study of 61 companies, we showed that the average age-inverse differences in supervisory relationships indirectly relate to company performance, and emotions play an important role in determining those effects. If the age gap is large, employees throughout the company are likely to experience negative emotions such as anger, fright, and disgust in the workplace, but if the age gap is small, employees are less likely to experience negative emotions. In turn, more frequent negative emotions among employees are associated with lower company performance. Hence, relational age differences between supervisors and older subordinates indirectly relate to poorer company performance by negatively influencing employee emotions. However, the unfavorable pattern is neutralized if older subordinates inhibit their negative emotions in encounters with their younger supervisors. Therefore, companies that have large average age-inverse differences in supervisory relationships but also employees who similarly suppress their emotions fare better than workplaces in which employees express their emotions more freely. In sum, inverse age differences between supervisors and subordinates matter, but not in a positive way: instead, such differences breed negative emotions that spread across the workforce unless subordinates suppress their emotions.

\section{Contributions}

Organizational demography research explores the relationship between the collective configuration of demographic characteristics and organizational outcomes (Lawrence 1997). With this study, we took that research further by casting companies as compositions of relationships marked by demographic similarities and differences. Specifically, we integrated compositional and relational demography research (Tsui et al. 1995) to show that relational age differences in the aggregate affect collective outcomes (i.e., emotions and performance). In prior demography research, compositional and relational approaches formed the bases for two distinct literatures. Compositional demography examines how organizational or group demographic compositions affect collective processes, states, and outcomes (for overviews see Joshi \& Roh 2009; Van Dijk et al. 2012). In contrast, relational demography investigates how demographic differences between employees and their peers or supervisors influence individual behaviors, processes, and outcomes (Tsui \& O'Reilly 1989). In this study, we integrated these two literatures by investigating how the average relational age differences between supervisors and older subordinates, as a compositional organizational property, affect emotions and company performance. Thus, one contribution this study makes follows from the linking of two separate literatures in demography research and involves the idea that organizations are composed of relationships.

Another related contribution of this research is the extension of age research to the organizational level. Previous research was mostly confined to individual, dyadic, or team levels. The evidence of relational demography research suggests that age-inverse supervisory relationships erode individual's work performance (Tsui \& O'Reilly 1989), lower an individual's job satisfaction, and increase the individual's burnout (Wesolowski \& Mossholder 1997). But findings at lower levels do not necessarily generalize to higher levels (Kozlowski \& Klein 2000), and studies at the organizational level are rare (Kunze et al., 2013; Kunze et al. 2011). By theorizing and investigating how age differences affect companies, we bridge the micro and macro domains of organizational research, offering evidence that company performance partly depends on relational age differences across the workforce hierarchy. Thus, 
our study demonstrates that relational age differences between supervisors and subordinates are relevant not only at the individual, dyadic, and group levels, but also impact entire companies. Organizational demography theory prior to our study had neglected such higher level outcomes of relational differences.

Apart from the primary contributions to age research in organizations, this study also holds implication for research on emotions. First is the extension of research about emotion effects to the organizational level of analysis. Thus, we contribute to the recent push toward examining emotions at levels beyond the small group (Menges \& Kilduff, 2015; Barsade \& O'Neill 2014; O’Neil \& Rothbard 2016). This research shows that workforce emotions matter for organizational performance. Second is the linking of emotion research with demography research-two literatures that rarely touch. Many factors influence how employees collectively feel at work (Barsade \& Knight 2015; Menges \& Kilduff 2015; Parke \& Seo 2016), but age differences are rarely listed among those factors. We theorize and show that, aside all other factors, age differences in supervisory relationships matter for emotions at work and that how they matter depends on emotion expression. Thus, seemingly superficial demographic characteristics link with deep psychological forces such as emotion; through these linkages, demographics affect outcomes. Although scholars have called for research on emotions and demographic differences (Ashkanasy \& Daus 2002), theory and empirical evidence about the role of emotions in the link between demographic differences and outcomes are rare. Our findings underpin the importance of such research and encourage investigations into other areas of demographic research such as gender and ethnicity.

The third contribution to emotion research concerns emotion expression and suppression. In addition to several studies at the individual level that have found emotion suppression to be a demanding, effortful and socially costly self-regulation strategy (e.g., Gross \& John 2003), we show that emotion suppression can be an effective strategy in circumstances that involve emotionally taxing social interactions. Specifically, in companies that have high average levels of age-inverse supervisory relationships our research found, with regard to organizational performance, that there are social benefits to emotion suppression within supervisory relationships. This finding should not be taken to imply that organizations should promote cultures of emotional suppression, in which a collective benefit is achieved through the psychological costs carried by individuals. Indeed, our findings also show that the well-known problems associated with emotion suppression do surface in companies with low average levels of age-inverse supervisory relationships. Specifically, Figure 3 illustrates that in companies with small or no age gaps between supervisors and subordinates, prevalent emotion suppression is associated with increased negativity. This finding corroborates existing evidence that emotion suppression can be detrimental (Gross \& Levenson 1997; Srivastava, Tamir, McGonigal, John, \& Gross 2009). When age norms are not violated and supervisory relationships are thus not tainted with negative emotions, emotion suppression is, indeed, damaging. In any case, companies are likely to be well advised to approach the challenges of age-inverse supervisory relationships in ways that benefit both the company at the organizational level and the employees at the individual level, rather than one or the other.

\section{Practical implications}

Our findings put to question contemporary promotion practices that disregard age as a criterion for placing a person into a supervisory role. This research points to the potential emotional and performance problems that go hand in hand with systematically promoting younger employees into positions that involve the management of older employees. An important practical implication therefore concerns the level of awareness concerning the potential problems of the new organizational order (cf. Cappeli \& Novelli 2010). We are not suggesting that companies should revert to the old workplace with traditional age structures. We also have no evidence to refute the effectiveness of merit-based promotion systems. But we do have evidence for some of the repercussions that companies are likely to face when moving away from traditional age structures and abandoning seniority-based promotion systems. This evidence casts doubt on the orthodoxy that merit-based performance systems are generally beneficial. Therefore, practitioners should carefully think about how they can avoid these repercussions in their companies. 


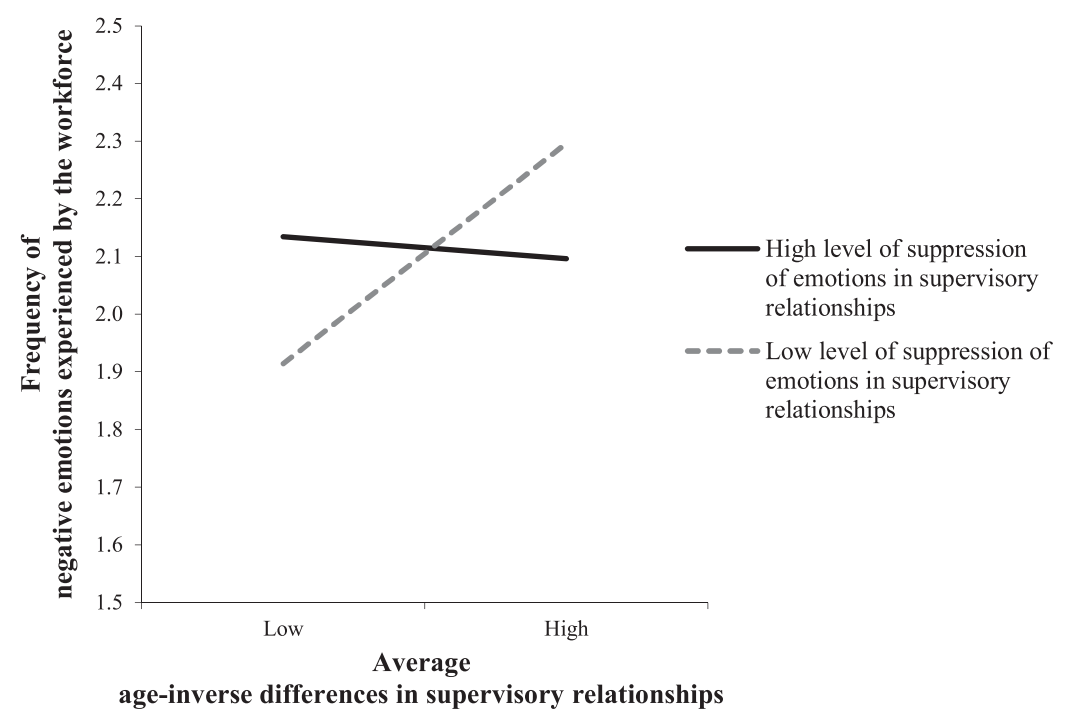

Figure 3. The interactive effect of average age-inverse differences and levels of emotion suppression in supervisory relationships on the frequencies of negative emotions experienced by the workforce

As a first step, practitioners could analyze the current setup of the relational age structure of their organization and then consider whether their organization is at risk. If there is a risk, the second step might involves examining whether HR records concerning promotion practices can be correlated with the organizational performance trajectory to detect any age-related effects. Furthermore, running an employee survey can help gauge whether emotions have tipped toward the negative. If the company is already affected by the dynamics we have identified, thus suffering negative emotions and performance decrements as a result of increasing average age differences between younger supervisors and older subordinates, then the third step involves finding and implementing solutions to escape this dynamic. Such solutions should not, however, build on emotion suppression. The rich evidence for the multiple negative consequences of emotion suppression for individuals (Gross \& Levenson 1997) would clearly render such solutions unethical. Employees could, however, be trained in emotion regulation strategies that help employees deal more effectively with their feelings (Koole 2009). For example, there is some evidence that emotional intelligence training can achieve such benefits for employees (Kotsou, Nelis, Grégoire, \& Mikolajczak 2011). Even better, in our view, would be to actively counter the underlying reasons for the negative emotions. If there were less emphasis on career time tables in companies and less hierarchical thinking, for example, then employees would likely respond less emotionally to age differences.

Such a development toward an age-bias free workplace can be supported by organizational initiatives identified in recent age diversity research. Boehm, Kunze, and Bruch (2014), for example, identified age-inclusive HR practices (i.e., human resource management practices that ensure an age-bias free workplace) as antecedents of a general positive age-diversity climate that beneficially impacts company performance. In another study Kunze, Boehm and Bruch (2013) showed that pro-diversity trainings and workshops can lower the negative effects of age diversity on company performance. To lower the negative consequences of age-inverse supervisory relationships, we would thus encourage similar HR and training initiatives.

\section{Limitations and future research}

The generalizability of our results is limited because the participating companies were from a single cultural environment. Germany is, however, an exemplary field setting in which to study the consequences of demographic 
change, because it has the world's fourth-highest median age of overall population (45.3 years in 2011; CIA World Factbook 2011). Thus, the age structure in German companies is a potential projection for future developments in other industrialized countries such as the United States, where the population is aging drastically but has not yet reached Germany's age level. The cultural patterns surrounding emotion expression are thought to be similar in Western countries, but are different to Asian cultures (Butler, Lee, \& Gross 2007), potentially limiting the universality of our findings.

Furthermore, this research does not allow us to draw statistical inferences about cause and effect. Our design features a fairly stable characteristic of the average age-inverse differences in supervisory relationships as an antecedent of the more volatile frequency of negative emotions and performance. Theoretically the flow of causality from stable characteristics to volatile outcomes is more likely than vice versa; thus, it is more likely that ageinverse differences in supervisory relationships caused the frequency of negative emotions than vice versa. We drew on extant theory to argue that negative emotions in the workforce affect company performance, but statistically we cannot exclude the possibility that the reverse holds true-that is, that company performance affects the emotions of the workforce. We did, however, test structural equation models in which we reversed the direction of effects and found no significant relationships. We also ran endogeneity analyses to gain confidence in the proposed model. And, we included performance in the previous year as a control variable, thus accounting for how past performance affects present emotions. The measure of past performance was somewhat limited because it was provided by HR rather than by the top management, and this likely accounts for the relatively weak relationship between prior and current performance in the bivariate correlation $(r=.36, p>.01)$ and the structural model $(b=.27)$. Overall, theory and empirical analyses supported the described direction of effects, but in absence of experimental data we cannot with certainty confirm the direction of the effects. We chose the current study design because it offers external validity and allows analyses at the organizational level, but experiments are indispensable to gain certainty about causality.

This study offers numerous avenues for future research. First, the integration of relational and compositional demography in terms of age sparks questions about how other facets of age and/or other demographic characteristics in the relationship between supervisors and subordinates affect feeling patterns and performance in organizations. In this research we focused on chronological age. Potentially, not only age, but generational differences in supervisory relationships (i.e., supervisor and followers from different birth cohorts that share distinct collective memories during formative years of life; Joshi, Dencker, Franz, \& Martocchio 2010) might relate to affective reactions in companies. Additionally, future studies can examine how deep-level differences such as personality traits and work values (e.g., Phillips \& Loyd 2006) affect relations and in turn organizational outcomes. Analogous to team faultline research (e.g., Jehn \& Bezrukova 2010), we assume that if age-inverse relationships are aligned with deep demographic characteristics, negative emotional tensions will increase; for example, if the younger supervisor is also more extroverted than the older subordinate. A misalignment might lower the organization-wide frequencies of negative emotion expression; for example, if the younger supervisor and the older subordinate are both extroverted.

Another direction for future research is to further examine the mechanisms that underpin the linkage between the average age-inverse difference in supervisory relationships and negative emotions. An anonymous reviewer suggested that procedural and distributive injustice might play a role in explaining the linkage. For example, if younger employees are promoted into supervisory positions because the promotion process is tweaked in their favor and discriminates against employees with higher age, older employees might experience negative emotions as a result of procedural injustice. Or, if the outcome of the promotion process leaves older employees in unfavorable positions, it is the inherent distributive injustice that creates negative emotions among employees. Such considerations are valuable in an effort to expand upon our model and gain a deeper understanding of the first-stage linkage between the average age-inverse difference in supervisory relationships and negative emotions. We did not have the data to test these suggestions, but we believe that future research should explore the role of procedural and distributive injustice—as well as other potential mechanisms - in the context of average age-inverse difference in supervisory relationships.

Future research should explore further contextual conditions (beyond emotion suppression) that may diminish the problems of age-inverse supervisory relationships or perhaps even bring about positive consequences. Could it be 
that age-inverse supervisory relationships are more painful in traditional, mechanistic organizations than in modern, organic organizations (Ambrose \& Schminke 2003)? Traditional organizations tend to be more hierarchical, thus reinforcing status and career norms, whereas modern organizations may be more egalitarian, thus downplaying the role of status and career progression. Indeed, there is the possibility that status norms and career norms are malleable (Posthuma \& Campion 2009) and that some organizations have evolved to overwrite these general norms with other specific norms that are less likely to evoke negative emotions in age-inverse supervisory relationships. In this context, the examination of age-related stereotypes, age norms, and anti-discrimination policies holds considerable promise (Kunze, Boehm, \& Bruch, 2013). Furthermore, to the extent that it becomes evident to older employees that they benefit from the promotion of younger employees into supervisory positions, older employees may find it easier to accept, perhaps even welcome pertinent promotion decisions. With respect to industry sectors, the correlations we found indicate that being in the service or manufacturing sector either increases or decreases, respectively, the magnitude of age inverse supervisory differences in companies. Our study only considered four rather broad measures of industry differences, so future research should examine more thoroughly the role of industry for our proposed relationships. For example, such research could investigate whether belonging to the high tech sector or the start-up sector would shape the effects we reported, because in these sectors younger employees are perhaps attributed higher expertise.

This study illuminates the role of emotions for demographic research, but much more research is needed to fully understand the emotional intricacies of diversity. For example, our research highlighted the effects of negative emotions such as anger, fury, and fright. A limitation of our research is that we did not measure these emotions with direct reference to age-inverse supervisory relationships; this avoided socially desirable responding, but also makes it harder to specifically attribute these emotions to age-inverse supervisor-subordinate relationships. Future research can explore how relational characteristics in organizations affect positive emotions such as joy, happiness, and enthusiasm. It is also important to consider the linkage between age-inverse supervisory relationships and emotions within the emotional climate of the work group, given that supervisors have considerable influence on how a work group feels (Ozcelik, Langton, \& Aldrich 2008). Are there ways that supervisors can make up for inverse age differences by fostering a positive emotional climate?

In our dataset, we found an interesting and unexpected positive correlation between the workforce's mean age and the frequency of negative emotions. Although the relationship was not significant in the full structural model with mean age as a covariate, it could be interesting to further investigate the relationship between an aging workforce and the emotions that prevail in organizations. Social psychology research suggests that older adults are generally happier than younger adults (Mroczek \& Kolarz 1998), but our data, in contrast, suggest that more frequent negative emotions were experienced in companies that have older employees. Thus, private life may be asymmetrical with business life regarding happiness among people of varying ages.

Moreover, future research could explore the role of emotion regulation strategies other than emotion suppression as boundary conditions for the age-related effects. Could the controlled expression of negative emotions in age-inverse supervisory relationships help resolve the hurt feelings of older subordinates? Although negative emotional disclosure can generally help resolve problems and strengthen relationships (Kennedy-Moore \& Watson 2001; Rimé 2007), such positive resolutions are unlikely in age-inverse supervisory relationships. First, the basic problem cannot be resolved: age differences cannot be changed. Second, when both parties trust and appreciate each other in friendly, communal relationships, emotion disclosures create and reinforce affective bonds, but between people of different status, disclosure tends to further deteriorate relationships (Phillips, Rothbard, \& Dumas 2009). When status differences cause the negative emotions, expressing those feelings further exacerbates the distance by bringing subtle conflicts and tensions to the surface. Nonetheless, even if expression is not helpful, other emotion regulation strategies such as reappraisal might be more effective than emotion suppression (Gross \& John 2003). Emotion reappraisal could thus be another interesting moderating variable for future studies. In sum, linking demography and emotion research generates a wide array of important research questions. 


\section{Conclusion}

This research suggests that the new organizational order is not necessarily better than the traditional age structure of the old workplace. Companies featuring high average age-inverse differences between supervisors and subordinates create emotional tensions that hurt the company's performance, if subordinates feel free to express emotions toward their supervisors. The key message of this article is that relational age differences matter not just for individuals, but that these differences accrue to affect entire organizations, both in terms of the feelings that are shared among the workforce and in terms of the performance that the company achieves.

\section{Author biographies}

Florian Kunze holds the chair for Organizational Studies at the University Konstanz, Germany. His current research interests include consequences of the demographic change for companies, within-group processes and dynamics in work teams and organizations, leadership research, and evidence-based human resource management strategies.

Jochen I. Menges holds the Chair of Leadership and HRM at WHU - Otto Beisheim School of Management in Düsseldorf, Germany (www.whu.edu/leadership). His research focuses on emotions in organizations, leadership, and work motivation.

\section{References}

Aiken, L. S., \& West, G. (1991). Multiple regressions: Testing and interpreting interactions. Thousand Oakes: Sage.

Akaike, H. (1987). Factor analysis and AIC. Psychometrika, 52, 317-332.

Ambrose, M. L., \& Schminke, M. (2003). Organization structure as a moderator of the relationship between procedural justice, interactional justice, perceived organizational support, and supervisory trust. Journal of Applied Psychology, 88(2), 295-305.

Anderson, J. C., \& Gerbing, D. W. (1988). Structural equation modeling in practice: A review and recommended two-step approach. Psychological Bulletin, 103(3), 411-423.

Antonakis, J., Bendahan, S., Jacquart, P., \& Lalive, R. (2010). On making causal claims: A review and recommendations. Leadership Quarterly, 21(6), 1086-1120.

Ashkanasy, N. M., \& Daus, C. S. (2002). Emotion in the workplace: The new challenge for managers. Academy of Management Executive, 16(1), 76-86.

Barsade, S. G. (2002). The ripple effect: Emotional contagion and its influence on group behavior. Administrative Science Quarterly, 47(4), 644-675.

Barsade, S. G., \& Gibson, D. E. (2007). Why does affect matter in organizations? Academy of Management Perspectives, 21(1), 36-59.

Barsade, S. G., \& Knight, A. P. (2015). Group affect. Annual Review of Organizational Psychology and Organizational Behavior, 2(1), 21-46.

Barsade, S. G., \& O'Neill, O. A. (2014). What's love got to do with it? A longitudinal study of the culture of companionate love and employee and client outcomes in a long-term care setting. Administrative Science Quarterly, 59, 551-598.

Bartel, C. A., \& Saavedra, R. (2000). The collective construction of work group moods. Administrative Science Quarterly, 45(2), 197-231.

Becker, T. E. (2005). Potential problems in the statistical control of variables in organizational research: A qualitative analysis with recommendations. Organizational Research Methods, 8(3), 274-289.

Bentler, P. M. (2007). On tests and indices for evaluating structural models. Personality and Individual Differences, 42(5), 825-829.

Bliese, P. D. (2000). Within group agreement, non-independence, and reliability. In K. J. Klein, \& S. W. Kozlowski (Eds.), Multilevel theory, research, and methods in organizations. San Francisco: Jossey-Bass.

Boehm, S. A., Kunze, F., \& Bruch, H. (2014). Spotlight on age-diversity climate: The impact of age-inclusive HR practices on firm-level outcomes. Personnel Psychology, 67, 667-704.

Brown, S. P., Westbrook, R. A., \& Challagalla, G. (2005). Good cope, bad cope: Adaptive and maladaptive coping strategies following a critical negative work event. Journal of Applied Psychology, 90(4), 792-798. 
Buengeler, C., Homan, A. C., \& Voelpel, S. C. (in press). The challenge of being a young manager: The effects of contingent reward and participative leadership on team-level turnover depend on leader age. Journal of Organizational Behavior DOI. 10.1002/job.2101.

Burke, M. J., Finkelstein, L. M., \& Dusig, M. S. (1999). On average deviation indices for estimating interrater agreement. Organizational Research Methods, 2(1), 49-68.

Butler, E. A., Gross, J. J., Philippot, P., \& Feldman, R. S. (2004). Hiding feelings in social contexts: Out of sight is not out of mind. In P. Philippot, \& R. S. Feldman (Eds.), The regulation of emotion (pp. 101-126). Mahwah, NJ: Lawrence Erlbaum.

Butler, E. A., Lee, T. L., \& Gross, J. J. (2007). Emotion regulation and culture: Are the social consequences of emotion suppression culture-specific. Emotion, 7(1), 30-48.

Cadsby, C. B., Song, F., \& Tapon, F. (2007). Sorting and incentive effects of pay for performance: An experimental investigation. Academy of Management Journal, 50(2), 387-405.

Cappeli, P., \& Novelli, B. (2010). Managing the older worker: How to prepare for the new organizational order. Cambridge: Harvard Business Press.

Castilla, E. J. (2008). Gender, race, and meritocracy in organizational careers. American Journal of Sociology, 113, 1479-1526.

Chan, D. (1998). Functional relations among constructs in the same content domain at different levels of analysis: A typology of composition models. Journal of Applied Psychology, 83(2), 234-246.

Cheung, G. W., \& Lau, R. S. (2008). Testing mediation and suppression effects of latent variables: Bootstrapping with structural equation models. Organizational Research Methods, 11(2), 296-325.

Chiang, F. F. T., \& Birtch, T. (2007). The transferability of management practices: Examining cross-national differences in reward preferences. Human Relations, 60(9), 1293-1330.

CIA World Factbook (2011). (accessed on 7 June 2013).

Clark, C. (1990). Emotions and micropolitics in everyday life: Some patterns and paradoxes of 'place'. In T. D. Kemper (Ed.), Research agendas in the sociology of emotions. Albany: State University of New York Press.

Cole, M. S., Walter, F., \& Bruch, H. (2008). Affective mechanisms linking dysfunctional behaviour to performance in work teams: A moderated mediation study. Journal of Applied Psychology, 93(5), 945-958.

Combs, J. G., Crook, T. R., \& Shook, C. L. (2005). The dimensionality of organizational performance and its implications for strategic management research. Research in Social Stratification and Mobility, 2, 259-286.

Cox, T., \& Nkomo, S. M. (1992). Candidate age as a factor in promotability ratings. Public Personnel Management, 21(2), 197-211.

Dasborough, M. T. (2006). Cognitive asymmetry in employee emotional reactions to leadership behaviors. Leadership Quarterly, $17(2), 163-178$.

Delaney, J. T., \& Huselid, M. A. (1996). The impact of human resource management practices on perceptions of organizational performance. Academy of Management Journal, 39(4), 949-969.

Dobson, J. R. (1988). Seniority promotion systems-A review. Personnel Review, 17(5), 19-28.

Elfenbein, H. A. (2007). 7 Emotion in organizations: A review and theoretical integration. The Academy of Management Annals, $1(1), 315-386$.

Elfenbein, H. A. (2014). The many faces of emotional contagion: An affective process theory of affective linkage. Organizational Psychology Review, 1-37.

Festinger, L. (1954). A theory of social comparison processes. Human Relations, 7(2), 117-140.

Frijda, N. H. (1988). The laws of emotion. American Psychologist, 43(5), 349-358.

Furunes, T., Mykletun, R. J., \& Solem, P. E. (2011). Age management in the public sector in Norway: Exploring managers' decision latitude. The International Journal of Human Resource Management, 22(06), 1232-1247.

Gross, J. J. (1998). The emerging field of emotion regulation: An integrative review. Review of General Psychology, 2(3), 271-299.

Gross, J. J. (2013). Emotion regulation: Taking stock and moving forward. Emotion, 13(3), 359-365.

Gross, J. J. (2002). Emotion regulation: Affective, cognitive, and social consequences. Psychophysiology, 39(3), $281-291$.

Gross, J. J., \& John, O. P. (2003). Individual differences in two emotion regulation processes: Implications for affect, relationships, and well-being. Journal of Personality \& Social Psychology, 85(2), 348-362.

Gross, J. J., \& Levenson, R. W. (1997). Hiding feelings: The acute effects of inhibiting negative and positive emotion. Journal of Abnormal Psychology, 106(1), 95-103.

Harber, K. D., \& Cohen, D. J. (2005). The emotional broadcaster theory of social sharing. Journal of Language and Social Psychology, 24(4), 382-400.

Hu, L., \& Bentler, P. M. (1999). Cutoff criteria for fit indexes in covariance structure analysis: Conventional criteria versus new alternatives. Structural Equation Modeling: A Multidiscipl inary Journal, 6(1), 1-55.

Hulland, J. (1999). Use of partial least squares (PLS) in strategic management research: A review of four recent studies. Strategic Management Journal, 20(2), 195-204.

Hughes, E. C. (1945). Dilemmas and contradictions of status. American Journal of Sociology, 50, 353-359.

Huselid, M. A. (1995). The impact of human resource management practices on turnover, productivity, and corporate financial performance. Academy of Management Journal, 38(3), 635-672. 
James, L. R., Demaree, R. G., \& Wolf, G. (1984). Estimating within-group interrater reliability with and without response bias. Journal of Applied Psychology, 69(1), 85-98.

James, L. R., Mulaik, S. A., \& Brett, J. M. (2006). A tale of two methods. Organizational Research Methods, 9(2), $233-244$.

Jehn, K. A., \& Bezrukova, K. (2010). The faultline activation process and the effects of activated faultlines on coalition formation, conflict, and group outcomes. Organizational Behavior and Human Decision Processes, 112(1), $24-42$.

Joshi, A., \& Roh, H. (2009). The role of context in work team diversity research: A meta-analytic view. Academy of Management Journal, 52(3), 599-627.

Joshi, A., Dencker, J. C., Franz, G., \& Martocchio, J. J. (2010). Unpacking generational identities in organizations. Academy of Management Review, 35(3), 392-414.

Kanter, R. M. (1977). Some effects of proportions on group life: Skewed sex ratios and responses to token women. American Journal of Sociology, 82(5), 965-990.

Karpinska, K., Henkens, K., \& Schippers, J. (2011). The recruitment of early retirees: A vignette study of the factors that affect managers' decisions. Ageing and Society, 31, 570-589.

Kelly, J. R., \& Barsade, S. G. (2001). Mood and emotions in small groups and work teams. Organizational Behavior and Human Decision Processes, 86(1), 99-130.

Kennedy-Moore, E., \& Watson, J. C. (2001). How and when does emotional expression help? Review of General Psychology, 5 (3), 187-212.

Kiefer, T. (2005). Feeling bad: Antecedents and consequences of negative emotions in ongoing change. Journal of Organizational Behavior, 26(8), 875-897.

Kilduff, M., Chiaburu, D. S., \& Menges, J. I. (2010). Strategic use of emotional intelligence in organizational settings: Exploring the dark side. Research in Organizational Behavior, 30, 129-152.

Knight, A. P., \& Eisenkraft, N. (2014). Positive is usually good, negative is not always bad: The effects of group affect on social integration and task performance. Journal of Applied Psychology.

Koole, S. L. (2009). The psychology of emotion regulation: An integrative review. Cognition and Emotion, 23(1), 4-41.

Kossek, E., Markel, K. S., \& McHugh, P. P. (2003). Increasing diversity as an HRM change strategy. Journal of Organizational Change Management, 16(3), 328-352.

Kotsou, I., Nelis, D., Grégoire, J., \& Mikolajczak, M. (2011). Emotional plasticity: Conditions and effects of improving emotional competence in adulthood. Journal of Applied Psychology, 96(4), 827-839.

Kozlowski, S. W. J., \& Klein, K. J. (2000). A multilevel approach to theory and research in organizations. In S. W. J. Klein, \& K. Klein (Eds.), Multilevel theory, research and methods in organizations (pp. 3-90). San Francisco: Josey-Bass.

Kunze, F., Boehm, S., \& Bruch, H. (2011). Age diversity, age discrimination, and performance consequences-A cross organizational study. Journal of Organizational Behavior, 32(2), 264-290.

Kunze, F., Boehm, S., \& Bruch, H. (2013). Organizational boundary conditions to prevent negative performance consequences of age diversity. Journal of Management Studies, 50(3), 413-442.

Kunze, F., de Jong, S. B., \& Bruch, H. (2016). Consequences of collective-focused and differentiated individual-focused leadership - Development and testing of an organizational-level model. Journal of Management, 42(4), 886-914.

Lawrence, B. S. (1980). The myth of the midlife crisis. Sloan Management Review, 21(4), 35-49.

Lawrence, B. S. (1984). Age grading: The implicit organizational timetable. Journal of Occupational Behaviour, 5(1), $23-35$.

Lawrence, B. S. (1988). New wrinkles in the theory of age: Demography, norms, and performance ratings. Academy of Management Journal, 31(2), 309-337.

Lawrence, B. S. (1997). The black box of organizational demography. Organization Science, 8(1), 1-22.

Lazarus, R. S. (1991). Emotion and adaptation. New York: Oxford University Press.

Lazear, E. P. (2000). Performance pay and productivity. The American Economic Review, 90, 1346-1361.

LeBreton, J. M., \& Senter, J. L. (2007). Answers to 20 questions about interrater reliability and interrater agreement. Organizational Research Methods, 11, 815-852.

Linton, R. (1936). The study of man. New York: Appelton-Century.

Little, T. D., Bovaird, J. A., \& Widaman, K. F. (2006). On the merits of orthogonalizing powered and product terms: Implications for modeling latent variable interactions. Structural Equation Modeling, 13(4), 479-519.

Losada, M., \& Heaphy, E. (2004). The role of positivity and connectivity in the performance of business teams. American Behavioral Scientist, 47(6), 740-765.

Mann, S. (1999). Emotion at work: To what extent are we expressing, suppressing, or faking it? European Journal of Work and Organizational Psychology, 8(3), 347-369.

Martin, J., Knopoff, K., \& Beckman, C. (1998). An alternative to bureaucratic impersonality and emotional labor: Bounded emotionality at The Body Shop. Administrative Science Quarterly, 43, 429-469.

Mathieu, J. E., \& Taylor, S. R. (2006). Clarifying conditions and decision points for mediational type inferences in organizational behavior. Journal of Organizational Behavior, 27(8), 1031-1056. 
Menges, J. I., \& Kilduff, M. (2015). Group emotions: Cutting the Gordian knots concerning terms, levels of analysis, and processes. The Academy of Management Annals, 9(1), 845-928.

Menges, J. I., Walter, F., Vogel, B., \& Bruch, H. (2011). Transformational leadership climate: Performance linkages, mechanisms, and boundary conditions at the organizational level. The Leadership Quarterly, 22(5), 893-919.

Mroczek, D., \& Kolarz, C. (1998). The effect of age on positive and negative affect: A developmental perspective on happiness. Journal of Personality and Social Psychology, 75(5), 1333-1349.

Ozcelik, H., Langton, N., \& Aldrich, H. (2008). Doing well and doing good: The relationship between leadership practices that facilitate a positive emotional climate and organizational performance. Journal of Managerial Psychology, 23(2), $186-203$.

O’Neil, O., \& Rothbard, N. (2016). Masculine emotional culture: The effects of joviality, companionate love, suppression, and work-family conflict on firefighter risk taking and health. Academy of Management Journal. doi: 10.5465/amj.2014.0952.

O'Reilly, C. A., \& Chatman, J. A. (1996). Culture as social control: Corporations, cults, and commitment. Research in Organizational Behavior, 18, 157-200.

Parke, M., \& Seo, M. G. (2016). The role of affect climate in organizational effectiveness. Academy of Management Review. 10.5465/amr.2014.0424.

Phelan, S. E., \& Lin, Z. (2001). Promotion systems and organizational performance: A contingency model. Computational \& Mathematical Organization Theory, 7(3), 207-232.

Perry, E. L., \& Finkelstein, L. M. (1999). Toward a broader view of age discrimination in employment-related decisions: A joint consideration of organizational factors and cognitive processes. Human Resource Management Review, 9(1), 21-49.

Perry, E. L., Kulik, C. T., \& Zhou, J. (1999). A closer look at the effects of subordinate-supervisor age differences. Journal of Organizational Behavior, 20(3), 341-357.

Peeters, M., \& Groot, L. (2012). Demographic change across the globe-maintaining social security in ageing economies. World Economics, 13(2), 75-97.

Phillips, K. W., \& Loyd, D. L. (2006). When surface and deep-level diversity collide: The effects on dissenting group members. Organizational Behavior and Human Decision Processes, 99(2), 143-160.

Phillips, K. W., Rothbard, N. P., \& Dumas, T. L. (2009). To disclose or not to disclose? Status distance and self-disclosure in diverse environments. Academy of Management Review, 34(4), 710-732.

Pierce, J. L., \& Gardner, D. G. (2004). Self-esteem within the work and organizational context: A review of the organizationbased self-esteem literature. Journal of Management, 30(5), 591-622.

Podsakoff, P. M., MacKenzie, S. B., \& Podsakoff, N. P. (2012). Sources/causes of common method bias in social science research and recommendations on how to control it. Annual Review of Psychology, 63(1), 539-569.

Posthuma, R. A., \& Campion, M. A. (2009). Age stereotypes in the workplace: Common stereotypes, moderators, and future research directions. Journal of Management, 35, 158-188.

Preacher, K. J., Rucker, D. D., \& Hayes, A. F. (2007). Addressing moderated mediation hypotheses: Theory, methods, and prescriptions. Multivariate Behavioral Research, 42(1), 185-227.

Randel, A. E. (2002). Identity salience: A moderator of the relationship between group gender composition and work group conflict. Journal of Organizational Behavior, 23(6), 749-766.

Richardson, H. A., \& Vandenberg, R. J. (2005). Integrating managerial perceptions and transformational leadership into a workunit level model of employee involvement. Journal of Organizational Behaviour, 26(5), 561-589.

Rimé, B. (2007). Interpersonal emotion regulation. In J. J. Gross (Ed.), Handbook of emotion regulation. New York: Guilford Press.

Rosenbaum, P. R., \& Rubin, D. B. (1983). The central role of the propensity score in observational studies for causal effects. Biometrika, 70(1), 41-55.

Seo, M.-G., Barrett, L. F., \& Bartunek, J. M. (2004). The role of affective experience in work motivation. Academy of Management Review, 29(3), 423-439.

Shaver, J. M. (2005). Testing for mediating variables in management research: Concerns, implications, and alternative strategies. Journal of Management, 31(3), 330-353.

Shore, L. M., Cleveland, J. N., \& Goldberg, C. B. (2003). Work attitudes and decisions as a function of manager age and employee age. Journal of Applied Psychology, 88(3), 529-537.

Srivastava, S., Tamir, M., McGonigal, K. M., John, O. P., \& Gross, J. J. (2009). The social costs of emotional suppression: A prospective study of the transition to college. Journal of Personality and Social Psychology, 96(4), 883-897.

Torchia, M., Calabro, A., \& Huse, M. (2011). Women directors on corporate boards: From tokenism to critical mass. Journal of Business Ethics, 102(2), 299-317.

Tsai, W. (2001). Knowledge transfer in intraorganizational networks: Effects of network position and absorptive capacity on business unit innovation and performance. Academy of Management Journal, 44(5), 996-1004.

Tsui, A. S., Egan, T. D., \& Xin, K. R. (1995). Diversity in organizations: Lessons from demography research. In M. M. Chemers, S. Oskamp, \& M. A. Costanzo (Eds.), Diversity in organizations: New perspective for a changing workplace. Washington DC: American Psychology Association. 
Tsui, A. S., \& O'Reilly, C. A. (1989). Beyond simple demographic effects: The importance of relational demography in superiorsubordinate dyads. Academy of Management Journal, 32(2), 402-423.

Tsui, A. S., Porter, L. W., \& Egan, T. D. (2002). When both similarities and dissimilarities matter: Extending the concept of relational demography. Human Relations, 55(8), 899-929.

Van Katwyk, P. T., Fox, S., Spector, P. E., \& Kelloway, E. K. (2000). Using the job-related affective well-being scale (JAWS) to investigate affective responses to work stressors. Journal of Occupational Health Psychology, 5(2), 219-230.

Van Dijk, H., Van Engen, M. L., \& Van Knippenberg, D. (2012). Defying conventional wisdom: A meta-analytical examination of the differences between demographic and job-related diversity relationships with performance. Organizational Behavior and Human Decision Processes, 119(1), 38-53.

Van Maanen, J., \& Kunda, G. (1989). "Real feelings": Emotional expression and organizational culture. Research in Organizational Behavior, 11, 43-103.

Vecchio, R. P. (1993). The impact of differences in subordinate and supervisor age on attitudes and performance. Psychology and Aging, 8(1), 112-119.

Wall, T. D., Michie, J., Patterson, M., Wood, S. J., Sheehan, M., Clegg, C. W., et al. (2004). On the validity of subjective measures of company performance. Personnel Psychology, 57(1), 95-118.

Wesolowski, M. A., \& Mossholder, K. W. (1997). Relational demography in supervisor-subordinate dyads: Impact on subordinate job satisfaction, burnout, and perceived procedural justice. Journal of Organizational Behavior, 18(4), 351-362.

Williams, L. J., \& O'Boyle, E. H. (2008). Measurement models for linking latent variables and indicators: A review of human resource management research using parcels. Human Resource Management Review, 18(4), 233-242.

Yang, J., \& Mossholder, K. W. (2004). Decoupling task and relationship conflict: The role of intragroup emotional processing. Journal of Organizational Behavior, 25(5), 589-605.

Zenger, T. R., \& Lawrence, B. S. (1989). Organizational demography: The differential effects of age and tenure distributions on technical communication. Academy of Management Journal, 32(2), 353-376. 